\title{
Development of Variable Camber Morphing Airfoil Using Corrugated Structure
}

\author{
Tomohiro Yokozeki ${ }^{1}$ and Aya Sugiura ${ }^{2}$ \\ The University of Tokyo, Tokyo, Japan, 113-8656 \\ and \\ Yoshiyasu Hirano $^{3}$ \\ Japan Aerospace Exploration Agency, Tokyo, Japan, 181-0015
}

\begin{abstract}
This paper describes the development and the wind tunnel test of a variable geometry morphing airfoil using corrugated structures. Proof-of-concept study of a morphing wing with corrugated flexible seamless flap-like structure is verified by the finite element analysis, and a prototype is manufactured using carbon fiber reinforced plastics. For the actuation system, two servomotors are installed inside the prototype wing to control the airfoil shape by the chord-wise tension of the connected wires. Successful actuation of the prototype wing is demonstrated under the air speed up to $30 \mathrm{~m} / \mathrm{s}$ in the wind tunnel test. Basic aerodynamic properties are also evaluated in comparison to traditional airfoil with a hinged control surface. Lift increase of variable corrugated wing is recognized compared to the traditional wing when the aileron angle increases.
\end{abstract}

\section{Nomenclature}

(Nomenclature entries should have the units identified)

$$
\begin{aligned}
& C_{L}=\text { Lift coefficient } \\
& C_{D}=\text { Drag coefficient } \\
& D=\text { Drag force, } \mathrm{N} \\
& L=\text { Lift force, } \mathrm{N} \\
& R e=\text { Reynolds number } \\
& S \quad=\text { Wing area, } \mathrm{m}^{2}
\end{aligned}
$$

\footnotetext{
${ }^{1}$ Associate Professor, Department of Aeronautics and Astronautics, 7-3-1 Hongo, Bunkyo-ku, Tokyo, 113-8656 Japan, AIAA Lifetime Member.

${ }^{2}$ Graduate Student, Department of Aeronautics and Astronautics, 7-3-1 Hongo, Bunkyo-ku, Tokyo, 113-8656 Japan

${ }^{3}$ Researcher, Institute of Aeronautical Technology, 6-13-1 Osawa, Mitaka, Tokyo, 181-0015 Japan
} 
$V=$ Air speed in the wind tunnel, $\mathrm{m} / \mathrm{s}$

$\alpha \quad=\quad$ Angle of attack of the wing model, degree

$\theta \quad=\quad$ Aileron angle or morphing angle, degree

$\rho \quad=\quad$ Air density, $\mathrm{kg} / \mathrm{m}^{3}$

\section{Introduction}

$\Lambda^{\mathrm{S}}$ world-wide air transportation volume is dramatically increasing, reduction of $\mathrm{CO}_{2}$ emissions and fuel consumptions is strongly required in the aircraft industry considering the environmental sustainability and the rising fuel prices. Many researchers are focusing on the morphing technology as a feasible way to enhance the flight efficiency and safety of the aircraft, and have been investigating the conceptual and experimental studies on the morphing aircraft all over the world [1-6]. It is expected that morphing aircraft or morphing wing contributes to the improvement of flight safety and environmental characteristics; e.g. the improvement of aerodynamic performance, the weight reduction of the ailerons and flaps, the noise reduction, and the multiplicity of flight control.

The present study aims to study the morphing wing which is capable of partial cross-sectional seamless change of the wing shape (e.g. two-dimensional variable airfoil, conformal trailing edge control surface), while dramatic geometric change of overall wing structure (e.g. significant change of wing area and sweepback angle)[7] is not focused on. The definition of the morphing has been recently discussed by Weisshaar [8]. The modern aircraft utilizes stiff structural materials including metals and composites. This means that flexible deformation of wing structures is impossible in reality, and hinged structures are used for the control surfaces. Morphing wing structures are responsible for load bearing capability for lifts and drags as well as flexible deformation. This contradicting requirement makes the development of the morphing wing difficult. There remain many structural challenges to develop the real and efficient morphing wings.

Recent advanced technology in structures and materials provide the new adaptive structures (bi-stable or multistable structures, compliant structures, smart structures using shape memory materials, etc.), and several morphing structures have been investigated [9-17]. Most of the researches are within conceptual studies, numerical simulation without experimental demonstration, development of partial prototype, or demonstration using micro air vehicles. Driving mechanism, control ability, load bearing capability, repeatability of morphing, and development of large 
size structures are still to be modified or solved. Thus, demonstration of morphing wings of large sized air vehicles has been rarely performed.

The authors proposed corrugated structures as shown in Fig. 1 for the morphing wing [18]. Corrugated structures have high load bearing capability in the direction perpendicular to corrugation, while flexible deformation is possible in the corrugation direction. This highly anisotropic characteristic motivates us to use corrugated structures for the morphing wing in the manner that corrugation direction (i.e. flexible direction) and perpendicular direction (i.e. stiff direction) coincide with chord direction and span direction of the wing, respectively. Several researches on morphing structures using corrugated structures follow recently [19-22]. It is expected that this structural concept is useful for realizing the variable camber airfoil or the conformal trailing edge control surface [23]. The aim of the present study is to demonstrate the applicability of corrugated structures to the variable camber morphing airfoil.

This paper describes the conceptual and manufacturing investigation of morphing wing using corrugated structures, and driving demonstration of the developed morphing in the wind tunnel test. A large sized morphing wing with partial use of corrugated structures in the trailing edge region is manufactured. Driving mechanisms are installed inside the wing structure. Feasibility of the manufacturing of morphing wing is confirmed, and the driving demonstration of the developed wing is performed in the wind tunnel test. In addition, aerodynamic performance of the developed morphing wing is also evaluated in comparison with the traditional hinged wing.

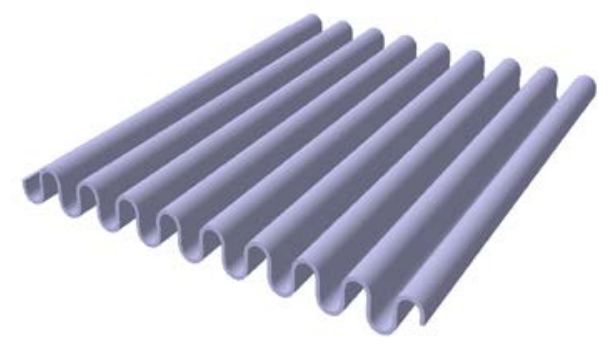

Fig. 1 Corrugated Structure

\section{Concept and Analysis of Morphing Wing}

\section{A. Overview of the Morphing Wing System}

The present study utilizes Wortmann FX63-137 airfoil (maximum thickness ratio: 13.7\%, camber ratio: 5.97\%) as a wing model. This airfoil is often used for motor gliders. Sizes of the morphing wing prototype are determined as 
$800 \mathrm{~mm}$ in the chord direction and $800 \mathrm{~mm}$ in the span direction (without taper) in reference to the real wing section with aileron of the motor glider HK36 (Diamond Aircraft Industries). The morphing section, consisting of corrugated structure, is defined as the trailing edge after $69 \%$ chord position of the airfoil. Note that the airfoil thickness at $69 \%$ chord position is about $50 \mathrm{~mm}$.

As a reference wing model, a hinged wing model is considered. The hinge line of the aileron of HK36 glider is located at $77 \%$ chord. The rear spar of the glider is located at about $65-70 \%$ chord. Therefore, a single-hinge aileron is attached at $77 \%$ chord position in the reference wing model. It should be noted that the morphing wing model has the rear spar at the same location as the glider and the above-mentioned morphing section (after 69\%). Because the present morphing wing (i.e. seamlessly variable camber wing) has no exact hinge axis, the aileron angle of the present morphing wing (called as morphing angle) is defined in the following way by the comparison with the hinged aileron; the aileron angle of the single-hinge aileron is defined as the rotation angle about the hinge axis; the line connecting between the leading edge and the trailing edge of the wing with a single-hinge aileron are defined as a function of the aileron angle, $\theta$, (positive downwards) as shown in the dashed red line in Fig. 2; the morphing angle of the present morphing wing is set as $\theta$ when the trailing edge of the morphing wing is located on the abovementioned line corresponding to the aileron angle, $\theta$. The terms "aileron angle" and "morphing angle" are utilized for the reference wing and the morphing wing, respectively, in the following texts. Note that deformation can only accomplished downward in the developed morphing wing as described below. Sanders et al. [23] compared aerodynamic performance of several kinds of conformal trailing edge control surfaces by setting the same trailing edge locations. The present paper follows the similar definition for morphing angle, although the control surface length is different between the morphing airfoil and the reference airfoil.

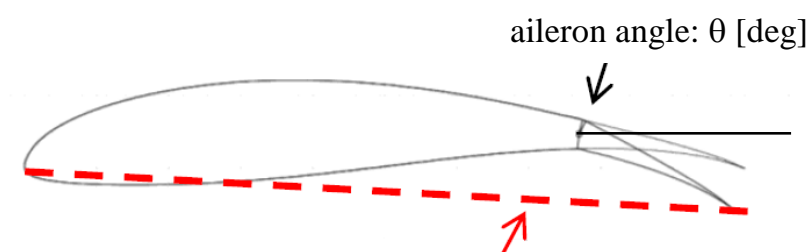

When the trailing edge of the morphing section is just on the dashed line, the morphing angle is set as $\theta$ corresponding to the hinged aileron. The red dashed line is defined by the leading edge and the trailing edge of the wing with a single-hinge aileron when the aileron angle is equal to $\theta$.

Fig. 2 Definition of Morphing Angle 


\section{B. Structure and Mechanism of the Morphing Section}

The core of morphing section is made of corrugated structure of which the overall envelope coincides with the shape of FX63-137 airfoil. Corrugated structure consists of C-shaped circular sections and vertically straight sections. The radius of all the circular sections is set to be $6 \mathrm{~mm}$. Uniform curves are utilized for the corrugated structure in the present study, although the corrugation geometry should vary when airfoil thickness changes from the optimal point of view. Corrugated region ranges from $69 \%$ chord position to $90 \%$ chord position. Thin plate is bonded to the upper surface of the corrugated structure to enhance the rigidity. A schematic of the corrugated morphing section with upper thin plate is shown in Fig. 3.

Wire tension is utilized to drive the morphing wing. An edge of the wire is attached to the trailing edge region, and the wire is placed through the corrugated structure near the lower wing surface. The other edge of the wire is connected to the servomotor mounted inside the wing, as shown in Fig. 4. Take-up motion of the wire by the motor induces the tension to the wire, resulting in downward deformation of the morphing section. The wires and the actuators are mounted near two span-wise edges of the wing in the present study. Owing to the highly anisotropic characteristic of the corrugated structure, span-wise uniform deformation of the wing with $800 \mathrm{~mm}$ span can be achieved by a small number (just one or two) of actuating systems.

Deformation can be accomplished only downwards using the present mechanisms. This may be useful for "flaps" and low speed maneuvers such as take-off and landing, but not useful for higher speed maneuvers, such as roll. For the axisymmetric deflections of the morphing section (i.e. one up, one down), the actuation mechanism should be modified.

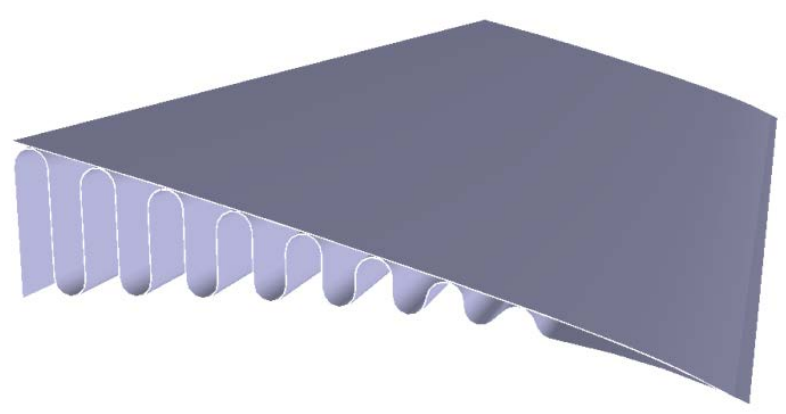

Fig. 3 Corrugated Morphing Wing with Upper Thin Skin 


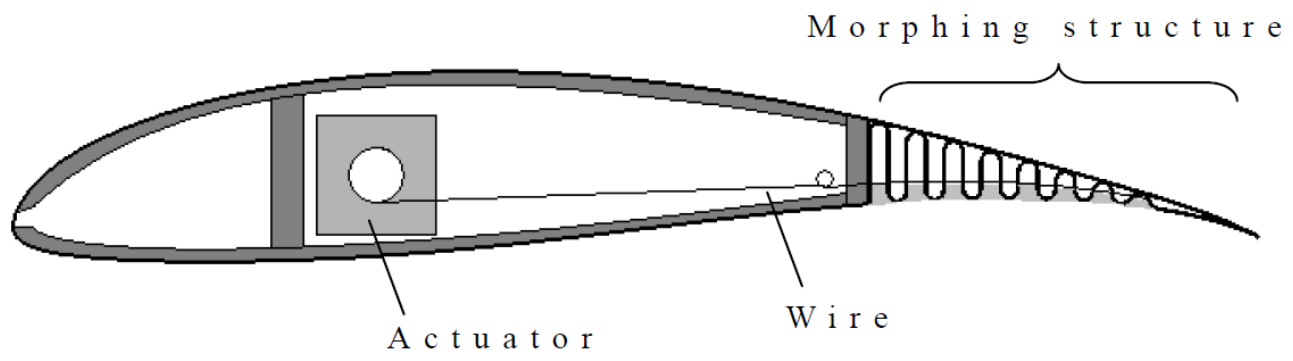

Fig. 4 Driving Mechanism of the Present Morphing Wing

\section{Analysis Model}

Deformation analysis of the proposed morphing wing is performed using the commercial FEM software (MSC Marc). The deformation of the morphing section and the necessary tension of the wire are estimated with consideration of geometric nonlinearity (i.e. large deformation) and contacts between the wire and the corrugated structure. As the present wing model is uniform in the span direction, two-dimensional analysis model is constructed using beam elements. The material is assumed to behave linear elastic, and the aerodynamic force is not considered herein.

Corrugated structure and upper thin skin are modeled by three-node shear deformable beam elements, and they are glued at contact points. The wire is modeled by two-node beam elements, and the end node is tied to the node of the corrugated structure at the vicinity of trailing edge. The FEM model is shown in Fig. 5.

The corrugated structure and the upper thin skin are fixed to the rigid rear spar and the stiff skin, respectively. The FEM model reflects these fixed conditions as shown in Fig. 5. In the morphing wing model, the wire penetrates through the corrugated structure. This means that the wire is constrained in the airfoil thickness direction, while it is able to move along the wire axis direction except the rightmost node tied to the corrugated structure. In the FEM model, small beam elements are prepared in the penetrated points of the corrugated structure. Sliding contact conditions are applied between these small beam elements and the wire elements (see Fig. 5). Note that friction is neglected between the small beam elements and the wire elements, although friction affects the wire tension, particularly at higher loads. The loading, $P$, is applied to the wire to the leading edge direction, and deformation of the morphing section is simulated. Material properties of CFRP [21] are used for simulation, and the thickness of the corrugated structure and the upper thin skin is set to be $0.5 \mathrm{~mm}$ (same as the real model described below). 


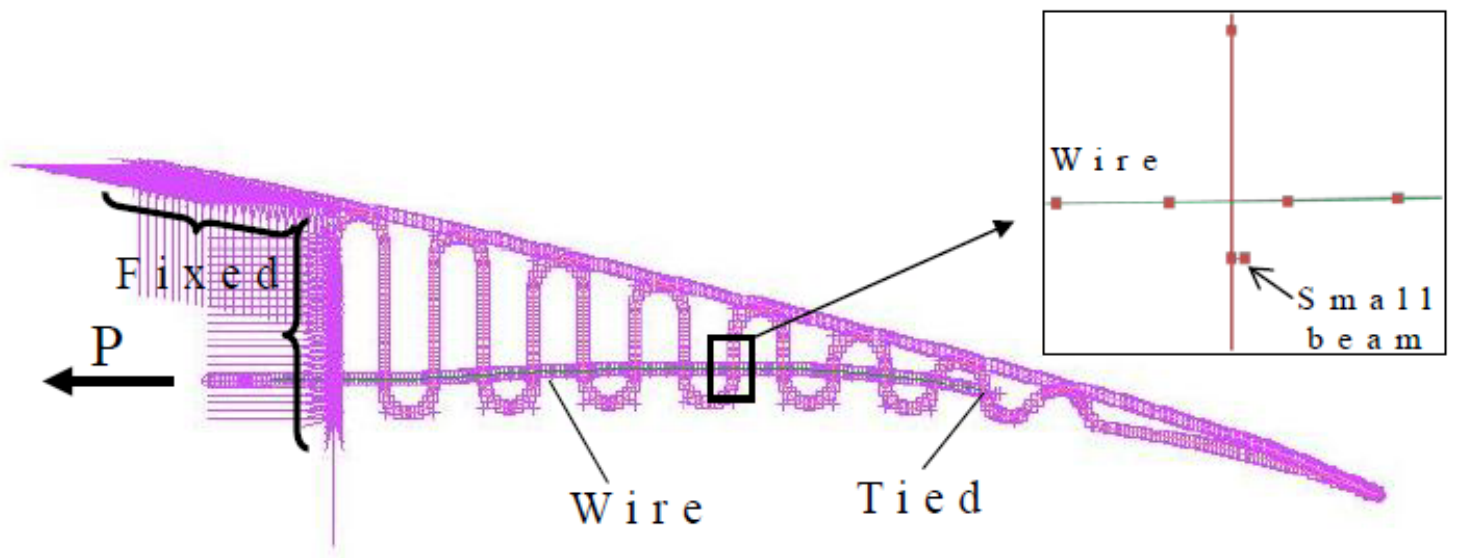

Fig. 5 FEM Model of Morphing Section

\section{Analytical Results}

The simulated deformations are summarized in Fig. 6 in the cases of $\theta=10$ and 20 degrees. The original shape (i.e. $\theta=0$ ) is also shown for comparison. The simulated locus of the trailing edge is plotted in Fig. 7, in which the definition lines of morphing angle are also indicated. The deformed shapes of the upper surface are shown in Fig. 8 when the morphing angles are 10 and 20 degrees. Experimental measured deflections (see the section III.C for the details of the measurement) are also presented in Fig. 8. Simulated results agree with the measurements, although manufacturing error of the airfoil shape and the resulting discrepancy between the two are somewhat recognized. Numerical simulation demonstrates that the driving of the present morphing wing is possible.

The simulated displacement at the loading point of the wire corresponds to the necessary reel length of the wire. The take-up length and the reaction force of the wire are plotted in Fig. 9 as a function of the morphing angle. This figure suggests that the take-up length and the tension increase almost linearly as the morphing angle increases. These results give us some knowledge to select the necessary servomotor for this morphing system. Wire tension increases to keep the morphing angle, when the aerodynamic forces are present. Therefore, we roughly estimated the additional wire tension owing to the lift forces of the morphing section, and then, selected the actuators. In addition, FEM simulation indicates that no severe stresses are induced in the structure during morphing. 

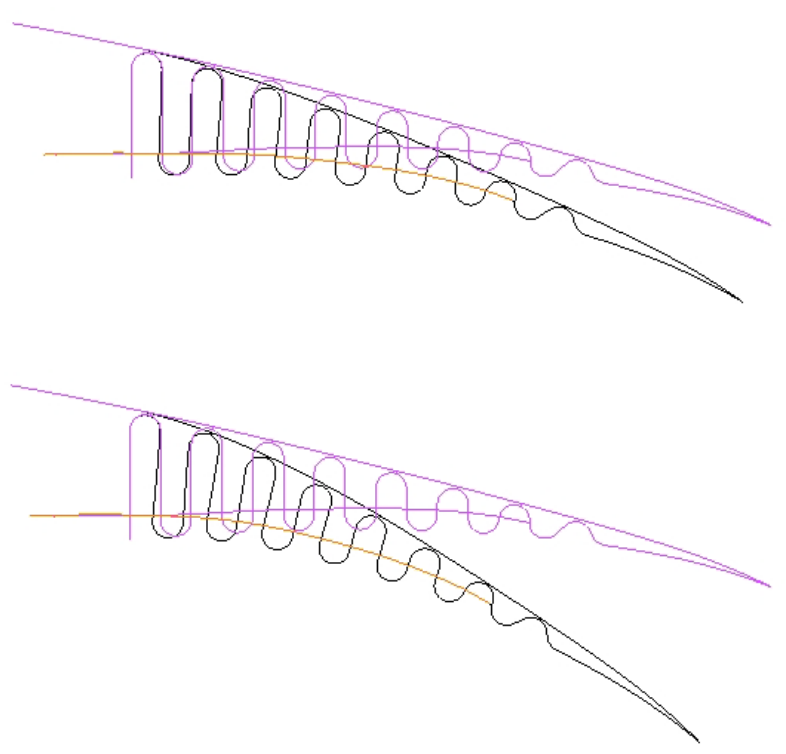

Fig. 6 Simulated Deformations: $\theta=10$ (upper figure) and $\theta=20$ (lower figure)

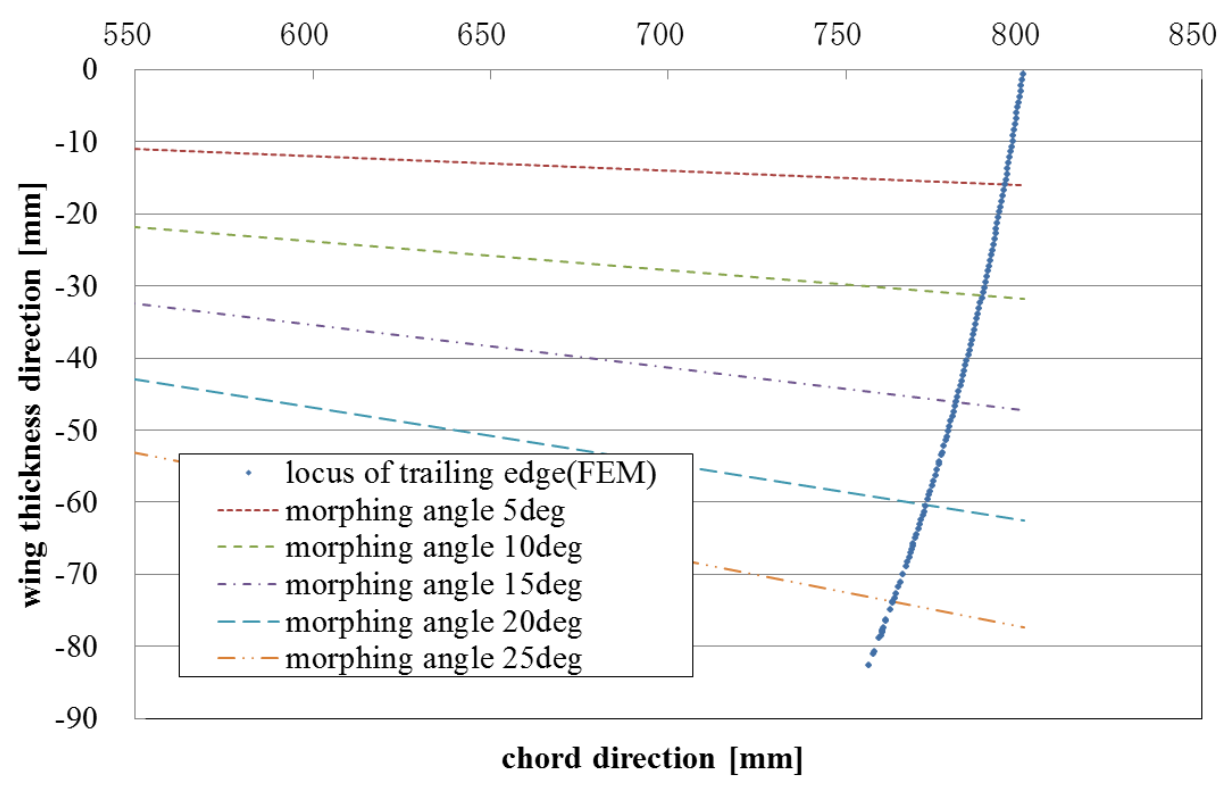

Fig. 7 Simulated Locus of Trailing Edge During Morphing 

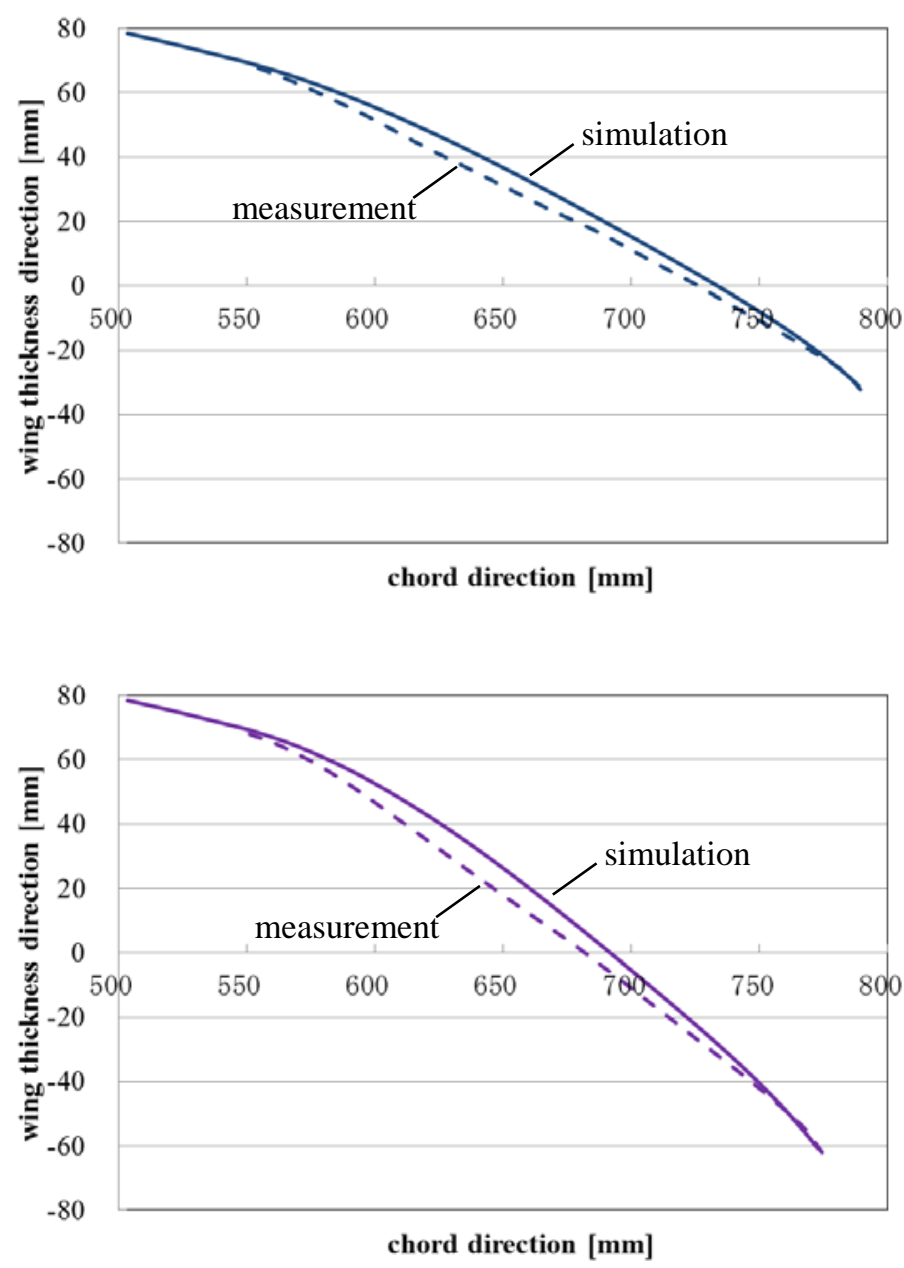

Fig. 8 Simulated and Measured Shapes of Upper Surface during Morphing: $\theta=10$ (upper figure) and $\theta$ $=20$ (lower figure)

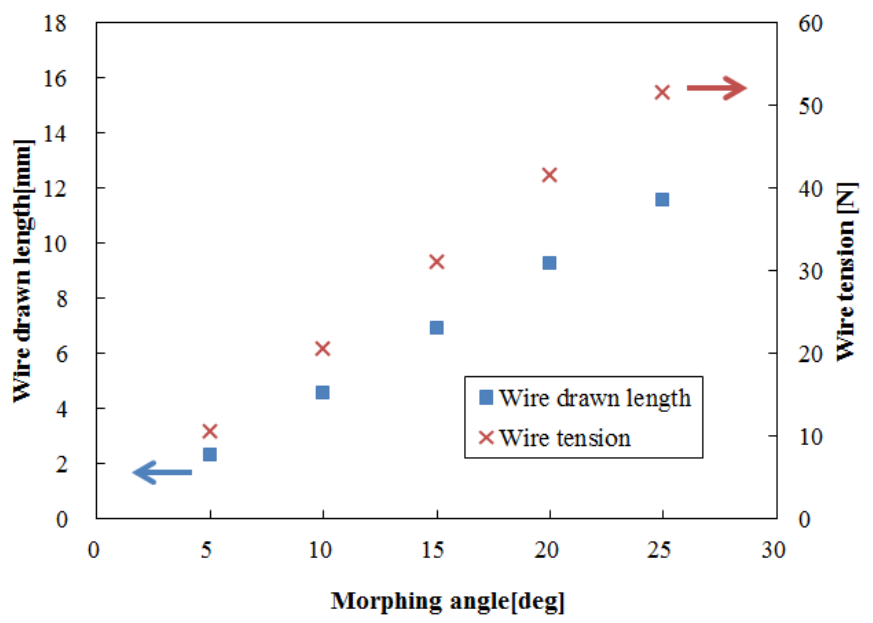

Fig. 9 Wire Take-up Length and Wire Tension as a Function of Morphing Angle 


\section{Manufacturing of Morphing Wing Model}

\section{A. Overview of Wing Model}

The above-described numerical simulation suggested that wire-driven actuating system is feasible for the present morphing wing. FX63-137 airfoil was used for the wing model, and the morphing wing prototype with $800 \mathrm{~mm}$ length in the chord direction and $800 \mathrm{~mm}$ length in the span direction without taper was manufactured herein. Two prototypes were prepared: morphing wing model consisting of morphing structure (after 69\% chord position) and reference wing model with a single-hinge aileron (after 77\% chord position).

\section{B. Morphing Wing Model}

Main wing is a hollow structure consisting of surface skins and front and rear spars. Wing skins (thickness is about 10mm) were made by sandwich structures using carbon fiber reinforced plastics (CFRP) as surface layers and plastic foam as a core. The front and rear spars were made of aluminum alloy and located at about $20 \%$ and $66 \%$ chord position, respectively. Morphing structure was glued to the rear spar.

Morphing structure consisted of corrugated structure and upper thin skin. Both are made of CFRP with two layer plain woven fabrics and epoxy (thickness is about $0.5 \mathrm{~mm}$ ), and bonded together. Corrugated structure ranged from $69 \%$ to $90 \%$ chord position, and after $90 \%$ chord position, foam core was inserted between the upper skin and the lower skin. Lower surface of the corrugate region was covered by thin plastic sheet (about $0.2 \mathrm{~mm}$ thickness). Crosssectional view of the morphing section is shown in Fig. 10.

Corrugated structure contained slits at the span-wise edges, and ring fixtures were attached to the slits for the installation of wires. The installed wire is shown in Fig. 11. The wires were connected to the trailing edge region. 

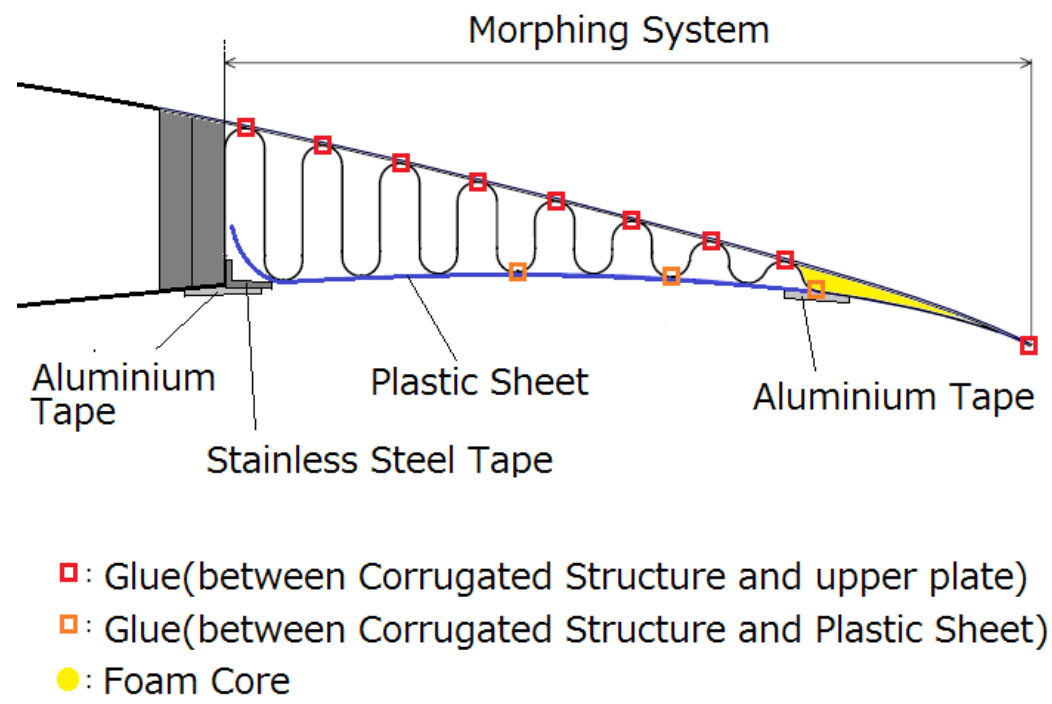

Fig. 10 Cross-Sectional View of the Morphing Section

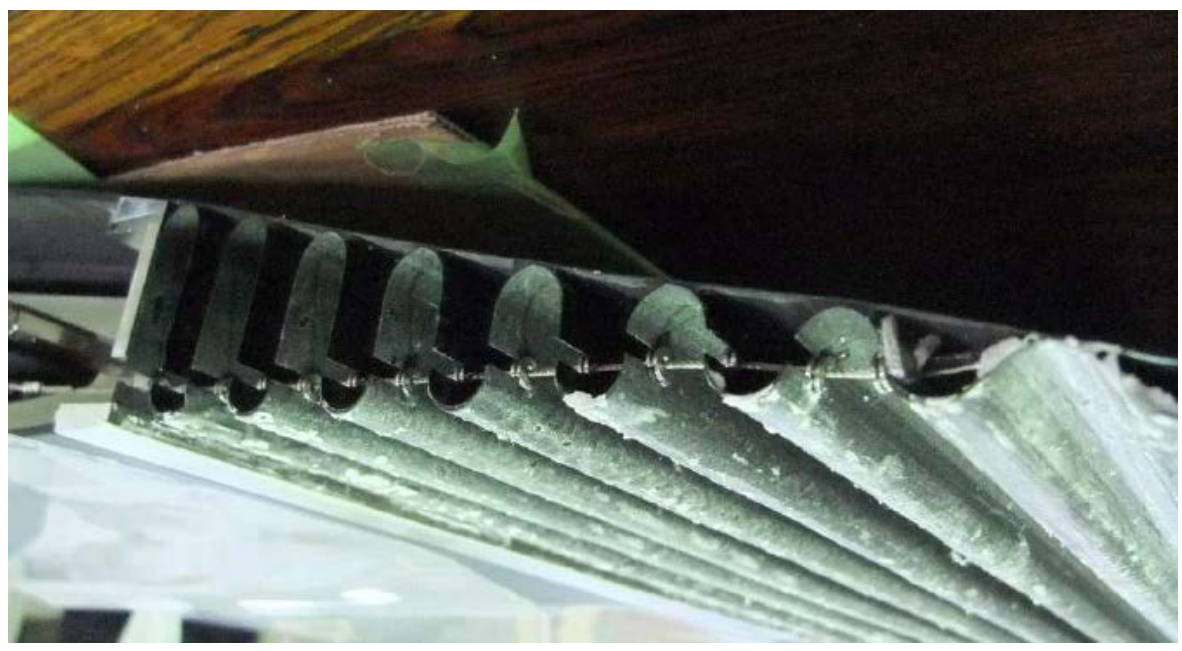

Fig. 11 Tension Wire Installed in the Corrugated Structure

Servomotor (NX65MA-PS25-3, Oriental Motor Co., Ltd.) was placed between the front and rear spars. Pulleys with $20 \mathrm{~mm}$ diameter are connected to the motor axes as shown in Fig. 12. Rotation of the motor induces the take-up motion of the wire, and consequently, downward deformation of the morphing section. On contrary, reverse rotation results in the recovery of the wing shape owing to the elastic restoring forces of the morphing structure. When the aerodynamic lifts are applied to the morphing section, aerodynamic forces also act to restore the shape. Two actuating systems were installed at the span-wise edges of the wing. The developed wing model undergoing the downward morphing of 35 degree is shown in Fig. 13. Successful driving of the developed wing model was confirmed. 


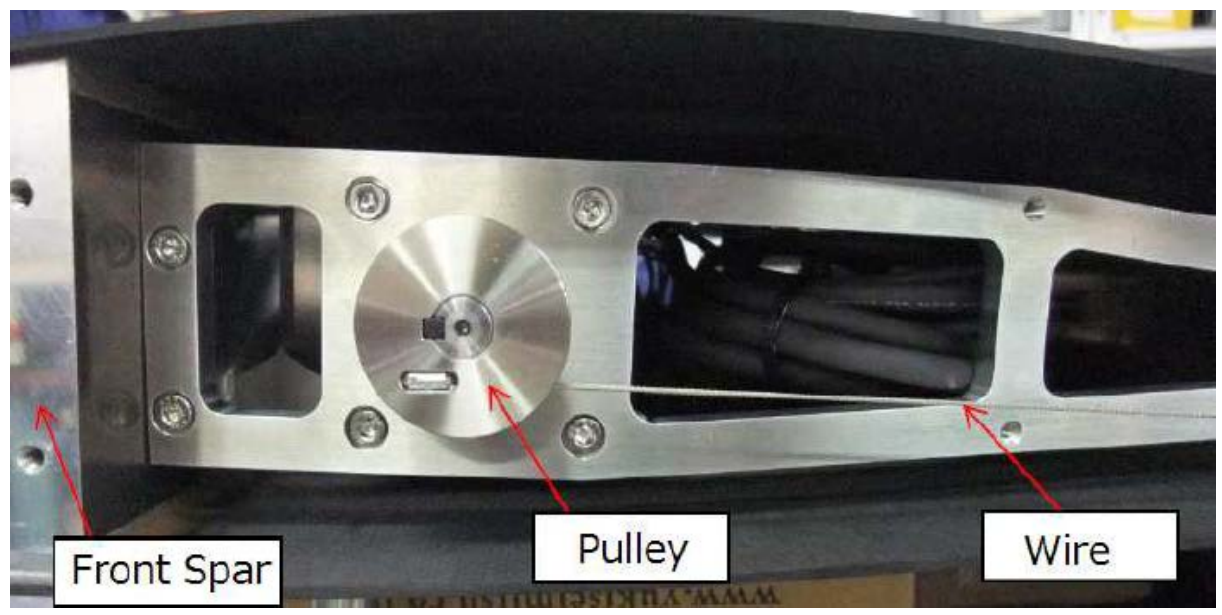

Fig. 12 Installed Motor in the Wing Model

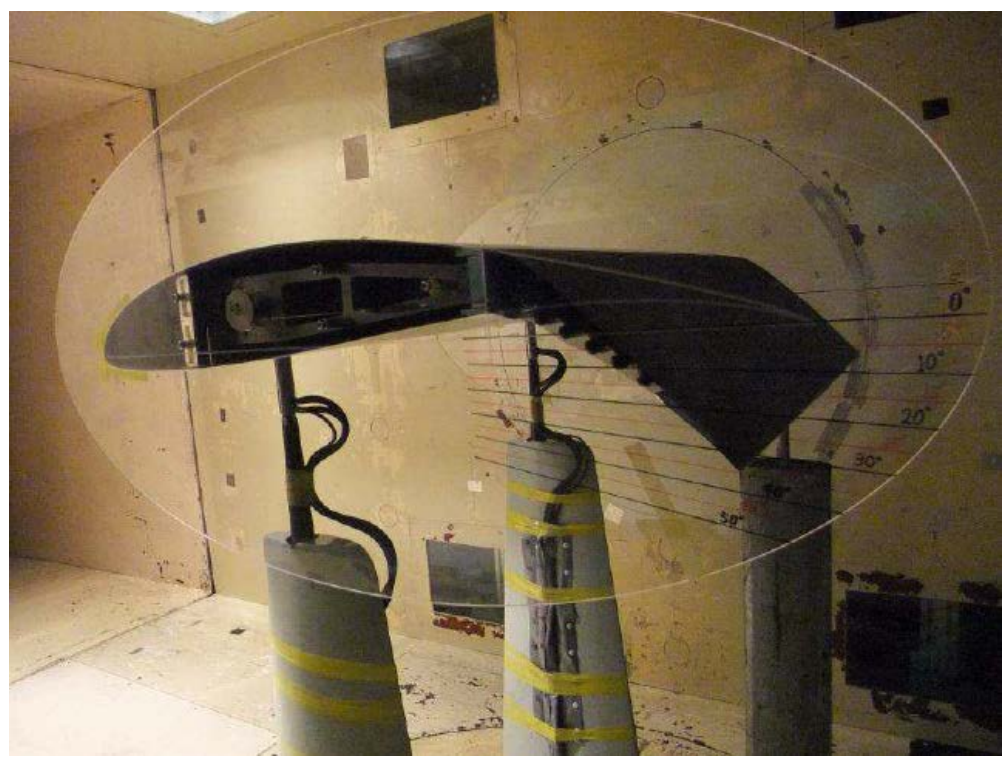

Fig. 13 Morphing Wing Model with Downward Morphing of 35 Degree

\section{Reference Wing Model}

As a reference wing model, $800 \mathrm{~mm} \times 800 \mathrm{~mm}$ wing model with single-hinge aileron was also manufactured. The hinge axis was located at 77\% chord position referring to the real wing of HK36 glider. Main wing and aileron structure were made of CFRP/foam-core sandwich structures. The front and rear spars were placed at about $20 \%$ and 72\% chord position, respectively. Two actuators were installed inside the wing between the front and rear spars.

The actuators were connected to the aileron by strut members at two span-wise edges of the wing. Holes were prepared in the rear spar, and strut members pass through the holes. The actuating system is shown in Fig. 14. 
The deformed shapes of upper surface were compared between the morphing wing and the reference wing as shown in Fig. 15. Solid and dashed lines depict morphing wing and the reference hinged wing, respectively. The deformed shapes were measured by non-contact laser scanning device, VIVID910 (Konica Minolta Inc.). Note that deformed shapes were measured under the condition without any aerodynamic forces, and the measured data were averaged in the span-wise direction. The simulated deformation in the previous analysis section also agrees with the measured shape for morphing wing (see Fig. 8).

It appears that the deformation of the morphing airfoil is similar to a linear flap at high morphing angles (see in the case of $\theta=30$ degree in Fig. 15). This result partially comes from the manufacturing error compared to the ideal airfoil shape and the manufactured corrugation geometry (see the difference between the simulated and the measured deformations in Fig. 8). In addition, we need to modify and optimize the corrugation geometry to achieve more seamless and smoother morphing deformation.

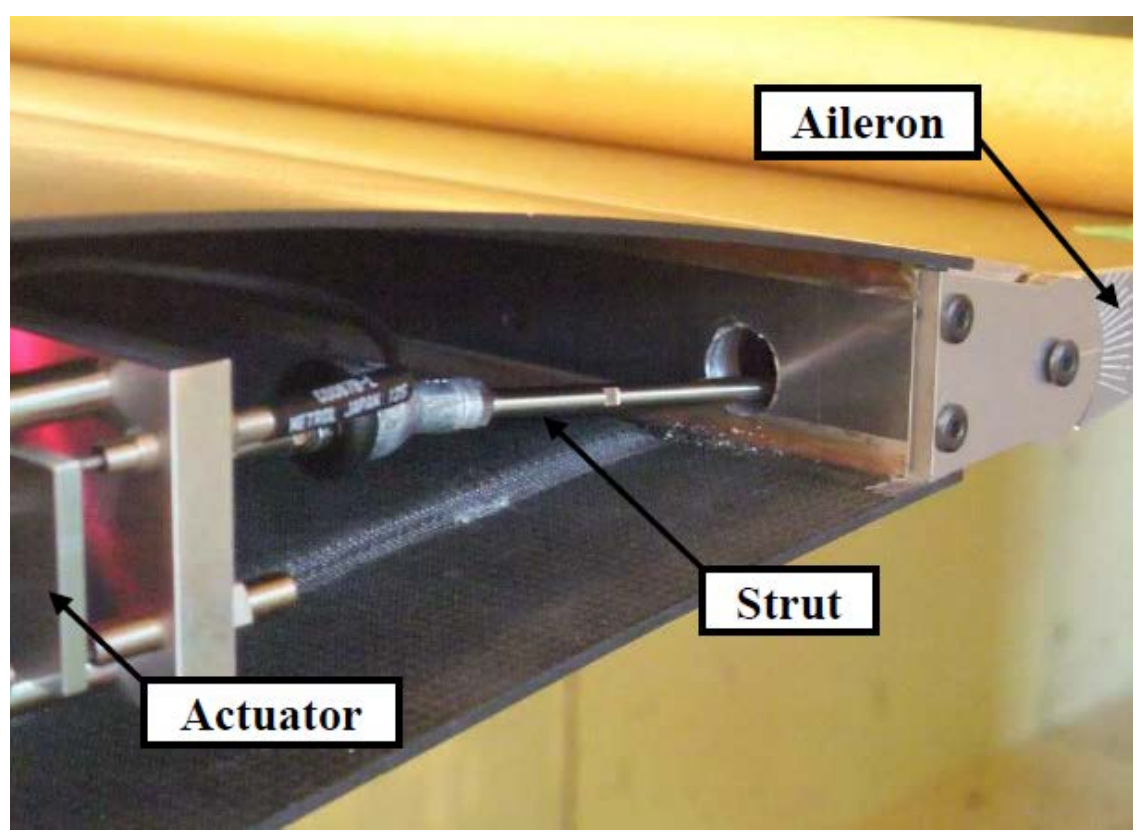

Fig. 14 Actuating System in the Reference Wing Model 

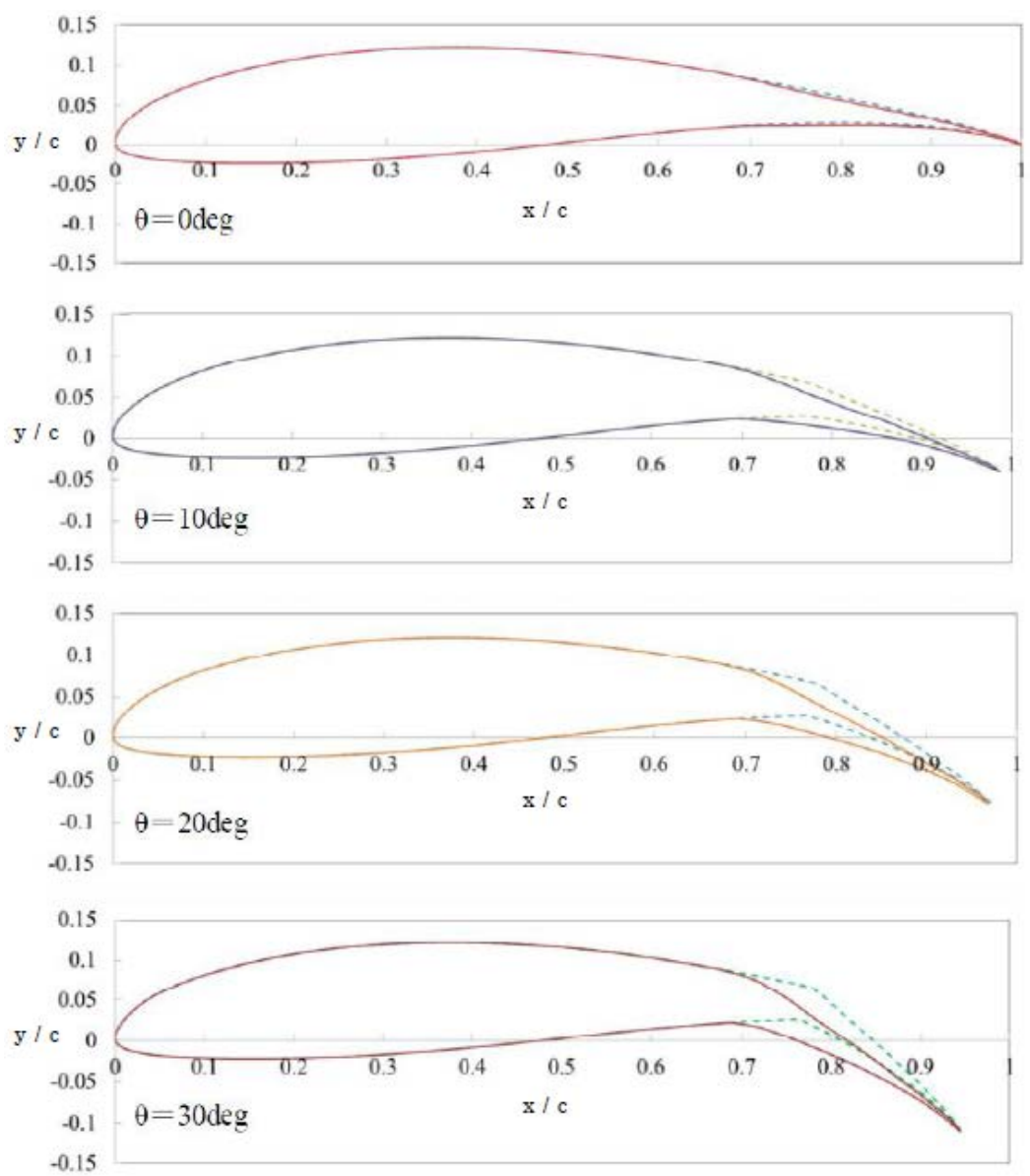

Fig. 15 Comparison of Deformation between Morphing Wing (Solid Line) and Reference Wing (Dashed Line)

\section{Wind Tunnel Test}

\section{A. Overview}

The manufactured wing models were utilized to demonstrate the morphing motion under the aerodynamic forces and to evaluate the aerodynamic characteristics. Specifically, the emphasis was placed on the driving demonstration of the developed morphing wing subjected to aerodynamic forces.

The test was performed in the low speed wind tunnel facility (Göttingen type) in JAXA. The test section is $2 \mathrm{~m}$ in width, $2 \mathrm{~m}$ in height, and $4 \mathrm{~m}$ in length. Wing model was supported by three struts (two were connected to the front spar, and the other one was connected to the rear spar). Aerodynamic forces were measured by the balance underneath the struts. 
The actuator system installed inside the wing models was wired to the controller outside the wind tunnel. Two small holes were prepared on the lower surface of the wing model, and the wires were pulled out and attached to the supporting front struts. Morphing motion could be controlled outside the wind tunnel during the test. The overall apparatus of wind tunnel test is shown in Fig. 16.

The manufactured wing models had low aspect ratio (i.e. span-to-chord ratio is equal to 1 ). This means that complex airstream was expected around the wing model, and the three-dimensional effect was significant. To mitigate the three-dimensional effect of airstream, two ellipsoidal wing-tip panels were attached to both edges of main wing (morphing section or aileron can move independently of the wing-tip panels). Ellipsoidal panels had $1000 \mathrm{~mm}$ major axis and $500 \mathrm{~mm}$ minor axis, and the major axis coincided with the chord direction. It should be noted that wing-tip panels induce additional drags during wind tunnel tests. Same wing-tip panels were attached to both the morphing wing model and the reference wing model, and the effect of wing-tip panels were included in the aerodynamic force data.

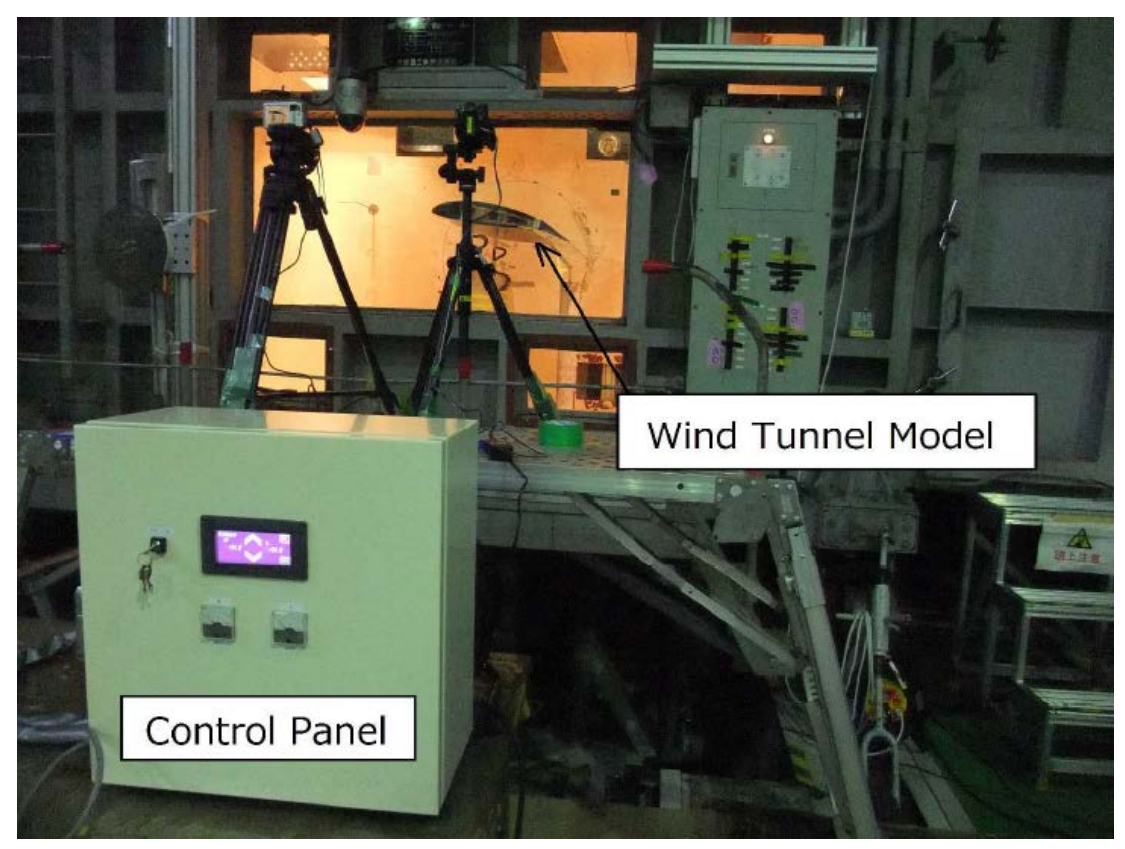

Fig. 16 Wind Tunnel Test of Morphing Wing

\section{B. Driving Demonstration}

Morphing motion was input to the morphing wing model subjected to aerodynamic forces in the constant air speed. Morphing angles were varied in reciprocal motion continuously from 0 degree to 40 degree under the 
conditions of air speed of 10,20 , and $30 \mathrm{~m} / \mathrm{s}$ (Re is about $5 \times 10^{5}, 1 \times 10^{6}$, and $1.5 \times 10^{6}$, respectively). Smooth morphing could be demonstrated without any harmful failure of the system. Morphing demonstration under the air speed of $30 \mathrm{~m} / \mathrm{s}$ is shown in Fig. 17. Under this condition, morphing section could move at about 5 degree per second.
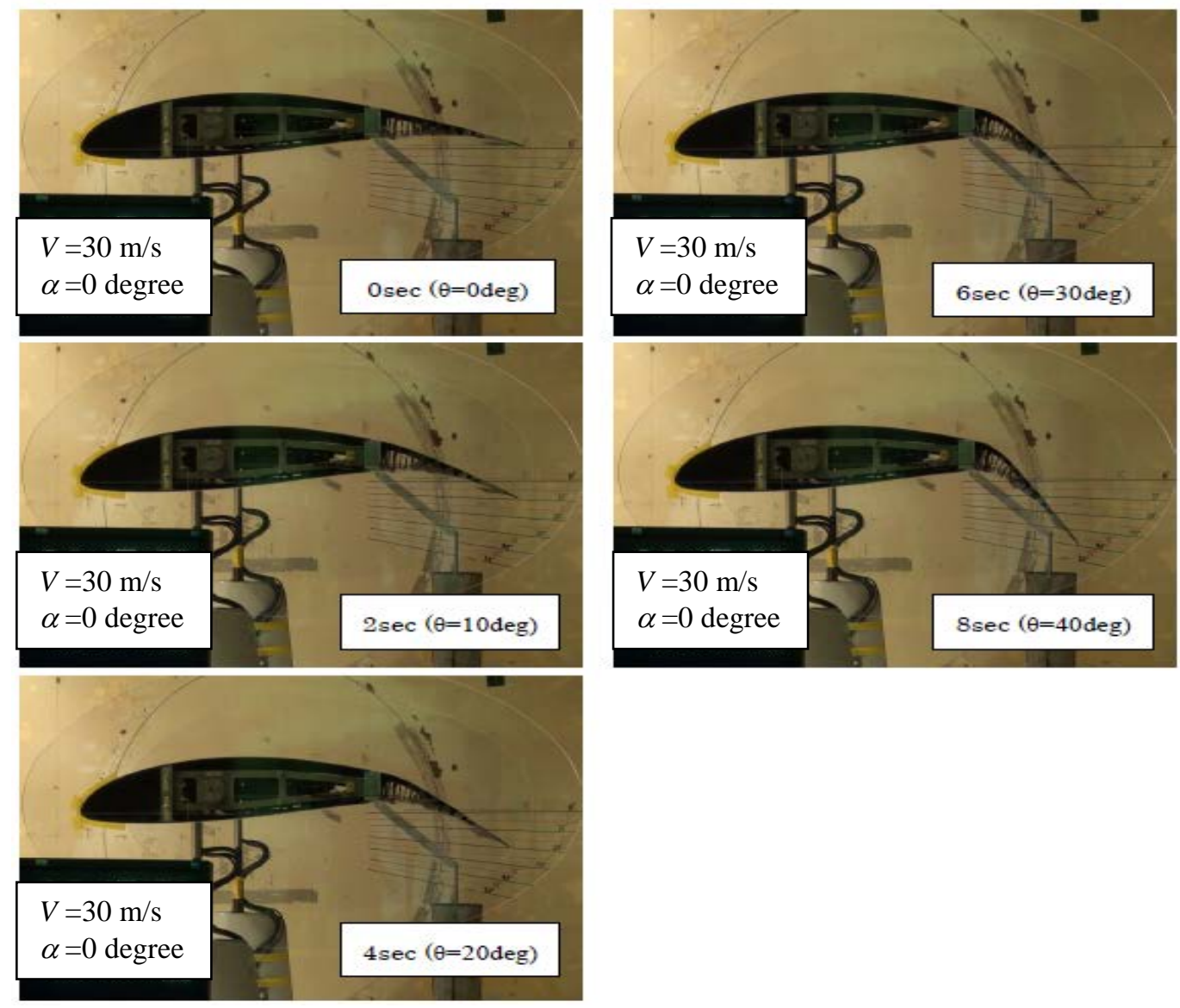

Fig. 17 Driving Demonstration of the Developed Morphing Wing under 30 m/s Air Speed

\section{Evaluation of Aerodynamic Characteristics}

Aerodynamic force measurements were conducted by varying the angle of attack, $\alpha$, in the cases of the following parameters;

Air speed, $V: 10,20,30 \mathrm{~m} / \mathrm{s}$

Morphing angle (or aileron angle), $\theta: 0$ - 40 degrees at 5-degree intervals 
Lift force $(L)$, drag force $(D)$ and moment were measured using the balance underneath the wind tunnel, and the lift coefficient $\left(C_{L}\right)$ and the drag coefficient $\left(C_{D}\right)$ were calculated using the following equation.

$$
C_{L}=\frac{L}{\frac{1}{2} \rho V^{2} S}, \quad C_{D}=\frac{D}{\frac{1}{2} \rho V^{2} S}
$$

Here, $S$ is the total wing planform area (i.e. $800 \mathrm{~mm} \times 800 \mathrm{~mm}=0.64 \mathrm{~m}^{2}$ ).

The obtained lift coefficients are compared between the morphing wing and the reference hinged wing in Fig. 18 when the air speed is $20 \mathrm{~m} / \mathrm{s}$ and $\theta$ is equal to 20 degrees. Note that data correction was applied considering the wall effect of wind tunnel [24]. In the case of morphing wing, the curve exhibited a bi-modal behavior and moderate lift drop was identified when $\alpha=10$ - 15 degrees. This phenomenon was recognized in all cases of morphing wing except $\theta=0$ degree. Prior to the above-mentioned lift drop (i.e. when $\alpha$ is small), the lift coefficients of morphing wing are high compared to the reference wing, while lift properties become similar beyond the lift drop (i.e. when $\alpha$ increases). One possible reason is that the flow separation occurred in both cases of the morphing wing and the hinged wing. Thus, aerodynamic properties were similar between the two at high angles of attack. It is estimated that the bi-modal behavior of aerodynamic characteristics comes from the airstream change in the morphing wing, however, the reason should be further investigated.

Comparison of drag polar ( $C_{L^{-}} C_{D}$ curve) is shown in Fig. 19, when air speed is $20 \mathrm{~m} / \mathrm{s}$. In the case of zero morphing or aileron angle (i.e. $\theta=0$ ), the polar curves are, of course, almost same between the morphing airfoil and the hinged airfoil. When $\theta$ increases, polar curve of morphing airfoil exhibit superior characteristics (in the range prior to lift drop observed in Fig. 18, i.e. low angles of attack) compared to the hinged airfoil (e.g. see $\theta=20$ ).

Lift coefficients are summarized as a function of $\theta$ in Fig. 20, when the air speed is $20 \mathrm{~m} / \mathrm{s}$. Linear region in $C_{L^{-}}$ $\theta$ curve is wide in the case of the morphing wing compared to the reference wing, indicating wide active aileron range and less flow separation in the case of morphing wing. In the case of hinged wing, curvature radius of the upper surface at the hinge axis has influence on the linearity in $C_{L^{-}} \theta$ curve [25], and larger curvature radius results in wider linear range. It is considered that similar effect happened to the present morphing wing. It is noted that morphing airfoil appeared to perform slightly worse than the hinged airfoil at low angles of attack. This may come from the fact that the shape of the manufactured upper surface of morphing section did not exactly match the ideal airfoil shape owing to manufacturing error. 


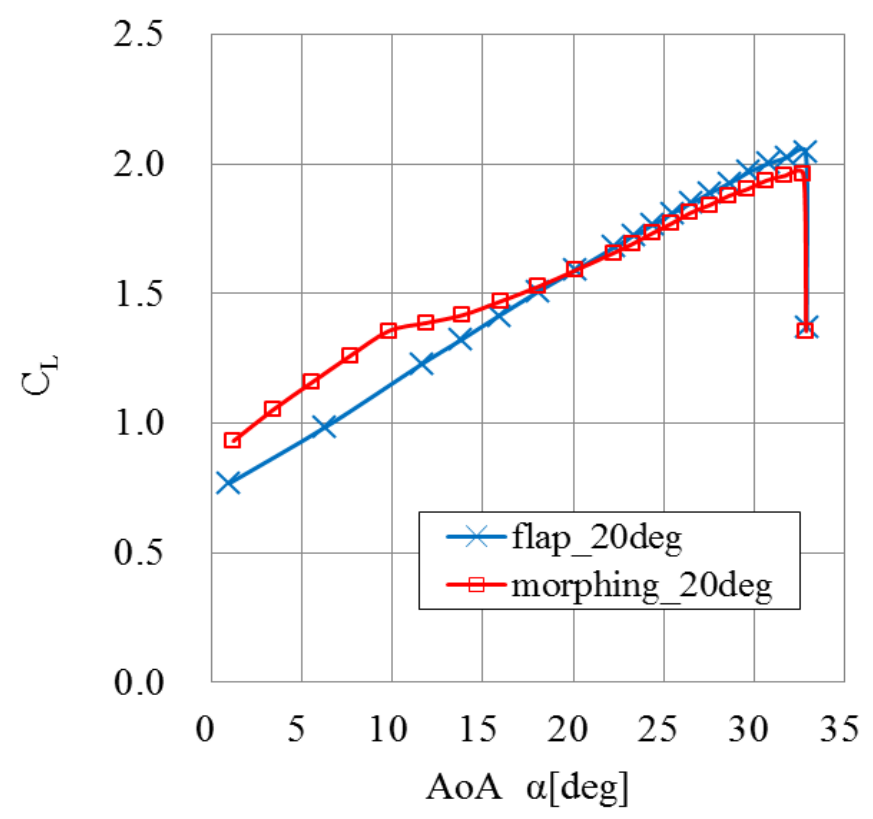

Fig. 18 Lift Coefficients as a Function of $\alpha(V=20 \mathrm{~m} / \mathrm{s}, \theta=20 \mathrm{deg})$

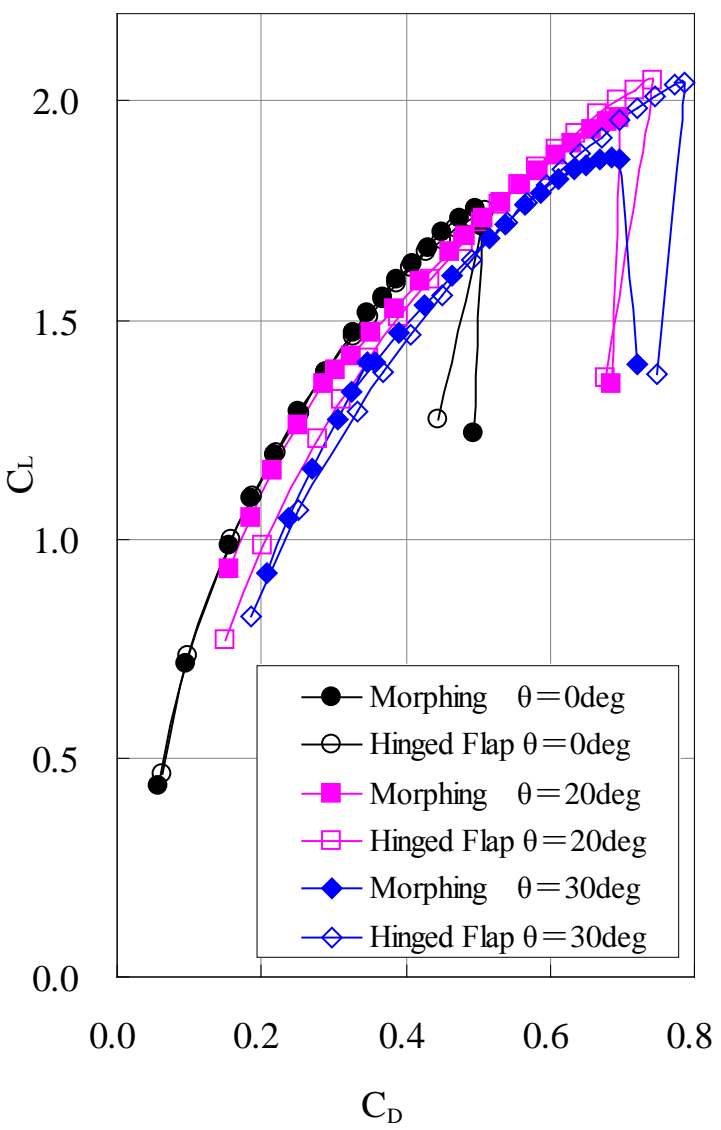

Fig. 19 Comparison of Polar Drag between the Morphing Airfoil and the Reference Airfoil ( $\mathrm{V=20}$ m) 
The present results indicate that morphing wing model exhibited superior properties in lift coefficients and linearity in $C_{L^{-}} \theta$ curve. The chord length of aileron in the reference wing is smaller than the chord length of morphing section in the morphing wing. In general, the airfoil with long chord length of aileron exhibits lower lift than the airfoil with short chord length when the position of trailing edge is same between the two. This comes from the fact that camber ratio of the former is lower than that of the latter. In the present study, the morphing wing has small camber ratio compared to the reference wing. However, the present experiment indicates the converse trend, i.e. $C_{L}$ of the morphing wing is higher than the reference wing. Consequently, it is considered that excellent properties of morphing wing result from the seamless morphing deformation, although further studies are necessary for the aerodynamic characteristics (e.g. three-dimensional effect).

In conclusion, the present study developed the actual-size morphing wing, demonstrated the driving of the morphing wing under the aerodynamic forces, and evaluated the aerodynamic performance of the morphing wing. The authors gained the knowledge, the methodology, and the experience to design and develop the morphing wing. Further development and application of the morphing wing is expected.

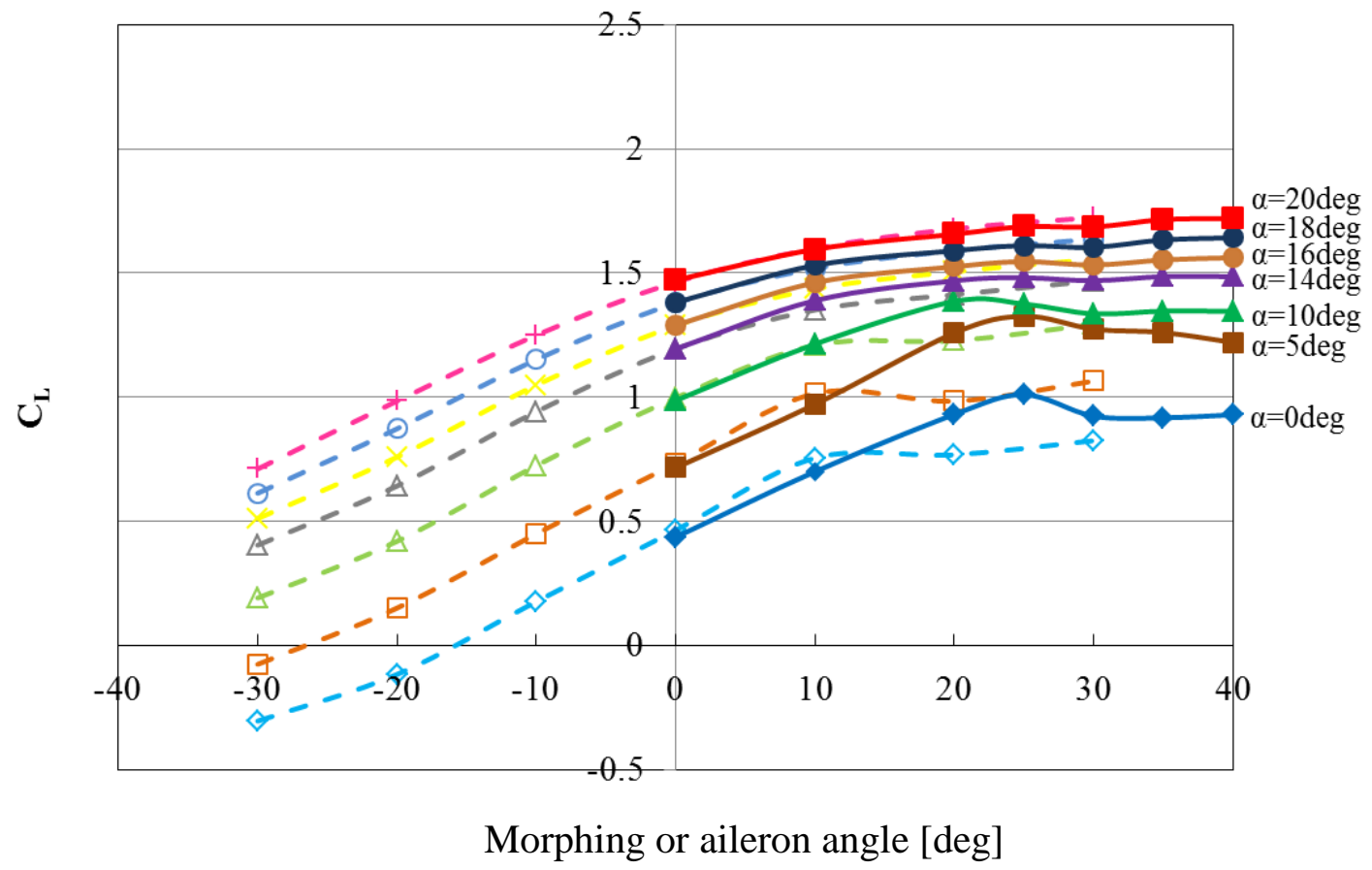

Fig. 20 Lift Coefficients as a Function of $\theta(V=20 \mathrm{~m} / \mathrm{s}$, Solid Line: Morphing Wing, Dashed Line: Reference Wing) 


\section{Conclusion}

The present study developed a method to realize a morphing wing with seamless deformable aileron using the corrugated structure and the actuation by the wire. Nonlinear finite element analysis was used to estimate the morphing deformation and the actuation force, and the feasibility of the present morphing system was confirmed. Morphing wing model with actuation system inside was successfully manufactured. Driving demonstration of the developed wing model was performed in the wind tunnel under the conditions of air speed of $10-30 \mathrm{~m} / \mathrm{s}(R e=$

$5 \times 10^{5}-1.5 \times 10^{6}$ ). Finally, aerodynamic characteristics of the morphing wing were evaluated in comparison with the hinged wing, suggesting that the morphing wing model exhibited superior properties in lift coefficients in $C_{L^{-}} \alpha$ curve and linearity in $C_{L^{-}} \theta$ curve. The present activity gives us the basic knowledge and the design methodology associated with morphing wing development.

\section{Acknowledgments}

This study was conducted under the financial support of Grant-in-Aid for Scientific Research (No. 24560970) by Japan Society for the Promotion of Science.

\section{References}

[1] Wlezien, R. W., Horner, G. C., McGowan, A. R., Padula, S. L., Scott, M. A., Silcox, R. J. and Simpson, J. O., “The Aircraft Morphing Program,” AIAA Paper 98-1927, 1998.

[2] McGowan, A. R., Washburn, A. E., Horta, L. G., Bryant, R. G., Cox, D. E., Siochi, E. J., Padula, S. L. and Holloway, N. M., “Recent Results from NASA’s Morphing Project,” Proceedings of SPIE, 4698, 2002, pp.97-111.

[3] Sofla, A. Y. N., Meguid, S. A., Tan, K. T. and Yeo, W. K., “Shape Morphing of Aircraft Wing: Status and Challenges,” Materials and Design, Vol. 31, No. 3, Mar. 2010, pp.1284-1292.

[4] Thill, C., Etches, J., Bond, I., Potter, K. and Weaver, P., “Morphing Skins,” The Aeronautical Journal, Vol. 112, Mar. 2008, pp.117-138.

[5] Tamayama, M., “Survey on Morphing Activities, “Nagare, Vol. 28, Aug. 2009, pp.277-284 (in Japanese).

[6] Barbarino, S., Bilgen, O., Ajaj, R. M., Friswell, M. I. and Inman, D. J., “A Review of Morphing Aircraft,” Journal of Intelligent Material Systems and Structures, Vol.22, No. 9, Jun. 2011, pp.823-877.

[7] Flanagan, J. S., Strutzenberg, R. C., Myers, R. B. and Rodrian, J. E., “Development and Flight Testing of A Morphing Aircraft, the NextGen MFX-1,” AIAA Paper 2007-1707, 2007. 
[8] Weisshaar, T. A, “Morphing Aircraft Systems: Historical Perspectives and Future Challenges.” Journal of Aircraft, Vol. 50, No. 2, MAr-Apr. 2013, pp.337-353.

[9] Diaconu, C. G., Weaver, P. M. and Mattioni, F., “Concepts for Morphing Airfoil Sections Using Bi-stable Laminated Composite Structures,” Thin-Walled Structures, Vol. 46, No. 6, Jun. 2008, pp.689-701.

[10] Campanile, L. F. and Sachau, D., “The Belt-rib Concept: A Structronic Approach to Variable Camber,” Journal of Intelligent Material Systems and Structures, Vol. 11, No. 3, Mar. 2000, pp.215-224.

[11] Wang, D. P., Bartley-Cho, J. D., Martin, C. A. and Hallam, B., “Development of High-rate, Large Deflection, Hingeless Trailing Edge Control Surface for the Smart Wing Wind Tunnel Model,” Proceedings of SPIE, 4332, 2001, pp.407-418.

[12] Ramrkahyani, D. S., Lesieutre, G. A., Frecker, M. and Bharti ,S., “Aircraft Structural Morphing Using Tendon Actuated Compliant Cellular Trusses,” AIAA Paper 2004-1728, 2004.

[13] Elzey, D. M., Sofla, A. Y. N. and Wadley, H. N. G., “A Shape Memory-based Multifunctional Structural Actuator Panel,” International Journal of Solids and Structures, Vo. 42, No. 7, Apr. 2005, pp.1943-1955.

[14] Wildschek, A., "Multi-Functional Morphing Trailing Edge Device for Control of All-Composite, All- Electric Flying Wing Aircraft,” AIAA Paper 2008-8956, 2008.

[15] Hetrick, J., Osborn, R. and Kota, S., “Flight Testing of Mission Adaptive Compliant Wing,” AIAA Paper 2007-1709, 2007.

[16] Bettini, P., Airoldi, A., Sala, G., Landro, L. D., Ruzzene, M. and Spadoni, A., “Composite Chiral Structures for Morphing Airfoils: Numerical Analyses and Development of a Manufacturing Process,” Composites Part B, Vol. 41, No. 2, Mar. 2010, pp.133-147.

[17] Bilgen, O., Butt, L. M., Day, S. R., Sossi, C. A., Weaver, J. P., Wolek, A., Mason, W. H. and Inman, D. J., “A Novel Unmanned Aircraft with Solid-state Control Surfaces: Analysis and Flight Demonstration,” Journal of Intelligent Material Systems and Structures, Vol. 24, No. 2, Jan. 2013, pp.147-167.

[18] Yokozeki, T., Takeda, S., Ogasawara, T. and Ishikawa, T., “Mechanical Properties of Corrugated Composites for Candidate Materials of Flexible Wing Structures,” Composites Part A, Vol. 37, No. 10, Oct. 2006, pp.1578-1586.

[19] Thill, C., Etches, J. A., Bond, I. P., Potter, K. D. and Weaver, P. M., “Composite Corrugated Structures for Morphing Wing Skin Applications,” Smart Materials and Structures, Vol. 19, No. 12, Dec. 2010, 124009.

[20] Kress, G. and Winkler, M., “Corrugated Laminate Homogenization Model,” Composite Structures, Vol. 92, No. 3, Feb. 2010, pp.795-810.

[21] Ge, R., Wang, B., Mou, C. and Zhou, Y., "Deformation Characteristics of Corrugated Composites for Morphing Wings,” Frontiers of Mechanical Engineering in China, Vol. 5, No. 1, Mar. 2010, pp.73-78.

[22] Yokozeki, T., Hatanaka, Y., Sugiura, A. and Hirano, Y., "Feasibility Study on the Composite Corrugation for Morphing Wing,” Proceedings of the $50^{\text {th }}$ Aircraft Symposium in Japan on Disc [CD-ROM], 2B-13, 2011, (in Japanese). 
[23]Sanders, B., Eastep, F. E. and Foster, E,. “Aerodynamic and Aeroelastic Characteristics of Wings with Conformal Control Surfaces for Morphing Aircraft,” Journal of Aircraft, Vol. 40, No. 1, Jan-Feb. 2003, pp.94-99.

[24] Rae Jr., W. H. and Pope, A., Low-Speed Wind Tunnel Testing, $2^{\text {nd }}$ ed., John Willey \& Sons Inc., Hoboken, 1999 , pp.362-432.

[25] Hoerner, L. A. and Borst, H. V., Fluid-Dynamic Lift, Hoerner Fluid Dynamics, New York, 1975, pp.(5-4)-(5-6). 